\title{
Participation in Self-Emulsification by Oil-Thin Film Voltammetry
}

\author{
Koichi Jeremiah Aoki ${ }^{1}$, Jie Yu ${ }^{1}$, Jingyuan Chen $^{1} \&$ Toyohiko Nishiumi ${ }^{1}$ \\ ${ }^{1}$ Department of Applied Physics, University of Fukui, Japan \\ Correspondence: Koichi Jeremiah Aoki, Department of Applied Physics, University of Fukui, Japan. E-mail: \\ kaoki@u-fukui.ac.jp
}

Received: November 12, 2013 Accepted: April 10, 2014 Online Published: April 22, 2014

doi:10.5539/ijc.v6n2p73

URL: http://dx.doi.org/10.5539/ijc.v6n2p73

\begin{abstract}
When an oil phase comes in contact with an aqueous phase, emulsions are formed spontaneously in each phase even without surfactant. The self-emulsification seems inconsistent with the electron transfer model proposed by Anson, in which ferricyanide in the aqueous phase is reduced at the oil/water interface by decamethylferrocene of the thin nitrobenzene phase. Anson's experimental data were here reproduced at slow scan voltammetry. However, the electron transfer model did not agree with our experimental results at high scan rates, in that the reduction wave of ferricyanide appeared without decamethylferrocene. Ferricyanide was demonstrated to pass through the nitrobenzene film in the form of aqueous droplets, which were adsorbed on the electrode surface. Formation of aqueous droplets can explain electrode reactions at carbon paste electrodes without including redox species in paste.
\end{abstract}

Keywords: thin-layer cell voltammetry at oil-coated film electrodes, self-emulsification at nitrobenzene/water interface, water droplets in oil phase, electron transfer mechanism

\section{Introduction}

Thin-layer cell voltammetry with an oil film is an electrochemical technique of detecting hydrophilic redox species with a help of chemical selectivity of oil-dissolved species (Shi \& Anson, 1998a, 1998b, 1999). The principle suggested by Anson, as illustrated in Figure 1(A), is composed of basically two concepts. (i) The hydrophilic reactant $\left(\mathrm{Fe}(\mathrm{CN})_{6}^{3-}\right)$ cannot reach the electrode surface by penetration of the oil phase. (ii) The hydrophobic reactant (decamethylferrocene $(\mathrm{DMFc})$ ) in the thin organic layer is oxidized by the electron transfer reaction with the hydrophilic species $\left(\mathrm{Fe}(\mathrm{CN})_{6}{ }^{3-}\right)$, and the oxidized one is reduced by the electrode reaction. The second step is a redox cycling, including diffusion back and forth in the oil film. The electron transfer mechanism at oil/water interface has been demonstrated through in-situ spectro-electrochemical technique (Ding et al., 1998). It has also been shown by scanning electrochemical microscopy, in which redox species generated at the oil/water interface is detected by the probe electrode close to the interface (Wei, Bard, \& Mirkin, 1995; Tsionsky, Bard, \& Mirkin, 1996, 1997). Various applications have been reported in the light of electron transfer mechanisms (Zhang, Barker, \& Unwin, 2000; Sun et al., 2003; Liu et al., 2005; Xu et al., 2004; Solomont \& Bard, 1995; Wang et al., 2003; Li et al., 2006; Michael et al., 2008; Quentel et al., 2007). The recent progress, the theory, the data analysis and applications have been reviewed (Lu et al., 2011), especially emphasizing electron transfer rates.

The concept of oil/water interface voltammetry assumes that the oil phase and the aqueous phase are separated unequivocally. The clear phase separation is, however, not guaranteed partly because of mutual dissolution (Samec \& Kakiuchi, 1990; Kakiuchi et al., 2003; Freire et al., 2008) and partly because of self-emulsification (Shchipunov \& Schmiedel, 1996; Pautot et al., 2003; Gonzalez-Ochoa, Ibarra-Bracamontes, \& Arauz-Lara, 2003; Sacanna, Kegel, \& Philipse, 2007). The latter occurs by mixing entropy (Aoki, 2011) even under quiescent conditions without including surfactants. Water droplets were found near the oil/water interface by an optical microscope (Aoki et al., 2009), while oil droplets were detected by dynamic light scattering and voltammetry ( $\mathrm{Li}$ et al., 2011). Thin layer-voltammograms may be influenced by formation of droplets in the oil film, and can be explained from a view point of self-emulsification rather than the electron transfer reactions. The emulsified aqueous droplets should contain $\mathrm{Fe}(\mathrm{CN})_{6}{ }^{3-}$, which can be reduced with $\mathrm{DMFc}$ in the oil phase, as is illustrated in Figure 1(B). This mechanism is close to the penetration mechanisms by Osakai (Hotta et al., 2003; Osakai et al., 2004). 


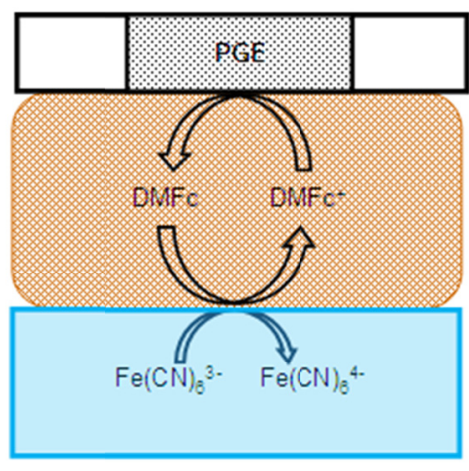

A

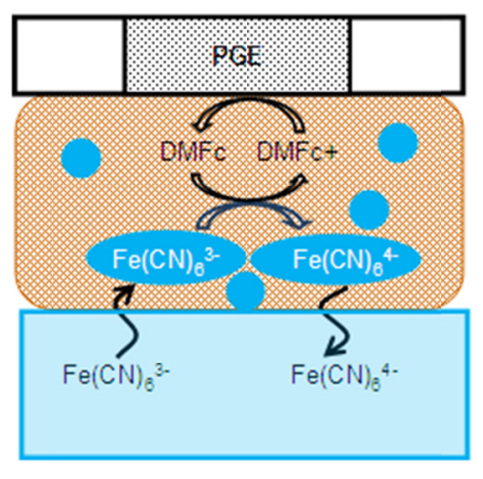

B

Figure 1. Electron transfer reaction models (A) at the oil/water interface and (B) within the oil film when $\mathrm{Fe}(\mathrm{CN})_{6}{ }^{3-}$ in the aqueous phase is reduced at the PGE mediated with DMFc

An application of a thin oil film is a carbon paste electrode (Adam, 1958), at which redox species in aqueous solution passes through hydrophobic oil layer to react at electrically percolated carbon powder. Carbon paste electrodes have exhibited chemical sensitivity and selectivity in electroanalysis with a help of suitable chemical modifiers (Kuwana \& French, 1964; Yao \& Musha, 1979; Ravichandran \& Baldwin, 1981; Kalcher, 1990). Concepts, fabrications and applications have been reviewed exclusively (Kalcher et al., 1995; Švancara et al., 2009). However, it is not clear why hydrophobic redox species can penetrate in thin oil film to reach the carbon electrode. When the paste does not contain any redox mediator, no reaction ought to occur according to Anson's model. The redox species might pass through the paste by self-emulsification to reach the carbon powder. This possibility would be explained by an extended concept of thin oil film voltammetry.

This report is devoted to re-investigation of Anson's thin oil-film voltammetry in the light of the emulsification. Our attention is paid to penetration of hexacyanoferrate into thin nitrobenzene film coated on the electrode. The reduction of hexacyanoferrate will be detected without any redox mediator in the oil phase.

\section{Experimental}

All the chemicals were used as received. Water was deionized and distilled. We purified nitrobenzene (NB) by mixing it with active alumina powder and centrifuging the solution for $5 \mathrm{~min}$. NB used for films was wet for immersing in water.

The optical microscope was a video microscope, VH-5000 (Keyence, Osaka). A potentiostat was Compactstat (Ivium, Netherlands). Pyrolytic graphite electrode (PGE) $3 \mathrm{~mm}$ in diameter was purchased (BAS, Tokyo). It was polished with alumina powder. It was coated with polyetheretherketone wall of $1.5 \mathrm{~mm}$ in thick. The reference and the counter electrodes were $\mathrm{Ag} / \mathrm{AgCl}(3 \mathrm{M} \mathrm{KCl})$ and platinum wire, respectively. The water phase was deaerated for 20 min before voltammetric run.

NB films were formed by injecting a known volume of NB on the PGE electrode by use of a micropipette. The injected NB was dispersed spontaneously on the electrode owing to the hydrophobicity of the electrode surface. The thickness of the film was evaluated by dividing the volume by the area of the electrode.

Thermogravimetric analysis (TGA) was made with TG-8125 (Rigaku, Tokyo). Amounts of samples were ca. 35 $\mathrm{mg}$. Temperature was increased at the rate of 20 degree $\mathrm{C}$ per min in nitrogen atmosphere. The size distribution of droplets was determined by a dynamic light scattering (DLS) instrument (Malvern Zetasizer Nano-ZS, UK).

\section{Results and Discussion}

\subsection{Reexamination of Anson's Experiment}

We followed the voltammetric runs under the conditions similar to those Anson et al used (Shi \& Anson, 1998b). We abbreviate the $0.1 \mathrm{M} \mathrm{NaCl}+0.1 \mathrm{M} \mathrm{NaClO}_{4}$ aqueous solution as $\{\mathrm{W}\}$, and $0.25 \mathrm{M}$ tetraheptylammonium perchlorate (THAP) solution as $\{\mathrm{O}\}$. The conditions as illustrated in Figure 2 were (a) $\{\mathrm{W}\}$ including $\mathrm{Fe}(\mathrm{CN})_{6}{ }^{3-}$, (b) $\{\mathrm{O}\}$ film on the PGE immersed in $\{\mathrm{W}\}$ including $\mathrm{Fe}(\mathrm{CN})_{6}{ }^{3-}$, (c) decamethylferrocene (DMFc)-including $\{\mathrm{O}\}$ film on the PGE immersed in $\{\mathrm{W}\}$, and (d) DMFc-including $\{\mathrm{O}\}$ film on the PGE immersed in the $\mathrm{Fe}(\mathrm{CN})_{6}{ }^{3-}$ including $\{\mathrm{W}\}$. We obtained voltammograms of (a)-(d) at $5 \mathrm{mV} \mathrm{s}^{-1}$ under the conditions similar to Anson's (Shi \& Anson, 1998b), and showed them in Figure 3(B). The voltammetric peaks at 0.18-0.25 V in (a) are due to the 
redox reaction of $\mathrm{Fe}(\mathrm{CN})_{6}^{3-/ 4-}$, which cannot be noticeable in (b) because of blocking of $\mathrm{Fe}(\mathrm{CN})_{6}^{3-}$ by the NB film. DMFc in the NB film showed the adsorption-like waves in (c), which belongs to a thin layer voltammogram. The cathodic wave in (d) is the catalytic current of $\mathrm{Fe}(\mathrm{CN})_{6}{ }^{3-}$ by the electron exchange reaction at the oil|water interface (Shi \& Anson, 1998b)

$$
\mathrm{Fe}(\mathrm{CN})_{6}^{3-}\{\mathrm{W}\}+\mathrm{DMFc}\{\mathrm{O}\} \rightarrow \mathrm{Fe}(\mathrm{CN})_{6}{ }^{4-}\{\mathrm{W}\}+\mathrm{DMFc}^{+}\{\mathrm{O}\}
$$

Our voltammograms in Figure 3(B) were essentially the same as Anson's (in Figure 3(A)). A feature of these voltammograms is disappearance of the redox wave at $0.18-0.25 \mathrm{~V}$ in (b) and (d). However, our voltammograms at scan rates over $30 \mathrm{mV} \mathrm{s}^{-1}$ exhibited the redox wave of $\mathrm{Fe}(\mathrm{CN})_{6}{ }^{3 / 4-}$ in (b) and (d). An example is shown in Figure $3\left(d^{\prime}\right)$. We examined the wave for (b) and (d) in detail by varying scan rates.

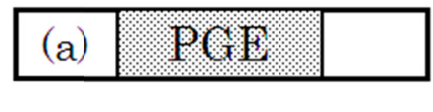

$\mathrm{Fe}(\mathrm{CN})_{6}{ }^{3}+\mathrm{H}_{2} \mathrm{O}+$ salt

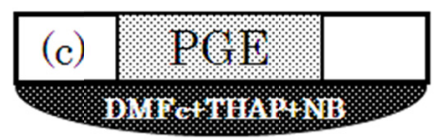

$\mathrm{H}_{2} \mathrm{O}+$ salt

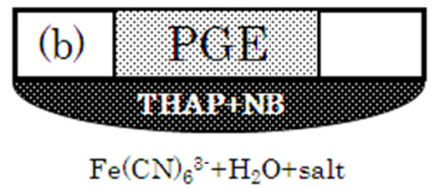

$\mathrm{Fe}(\mathrm{CN})_{6}{ }^{3+}+\mathrm{H}_{2} \mathrm{O}+$ salt

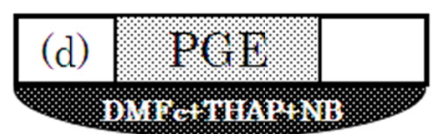

$\mathrm{Fe}(\mathrm{CN})_{6}^{3}+\mathrm{H}_{2} \mathrm{O}+$ salt

Figure 2. Illustrations of the oil and the aqueous phases with four combinations of solution compositions
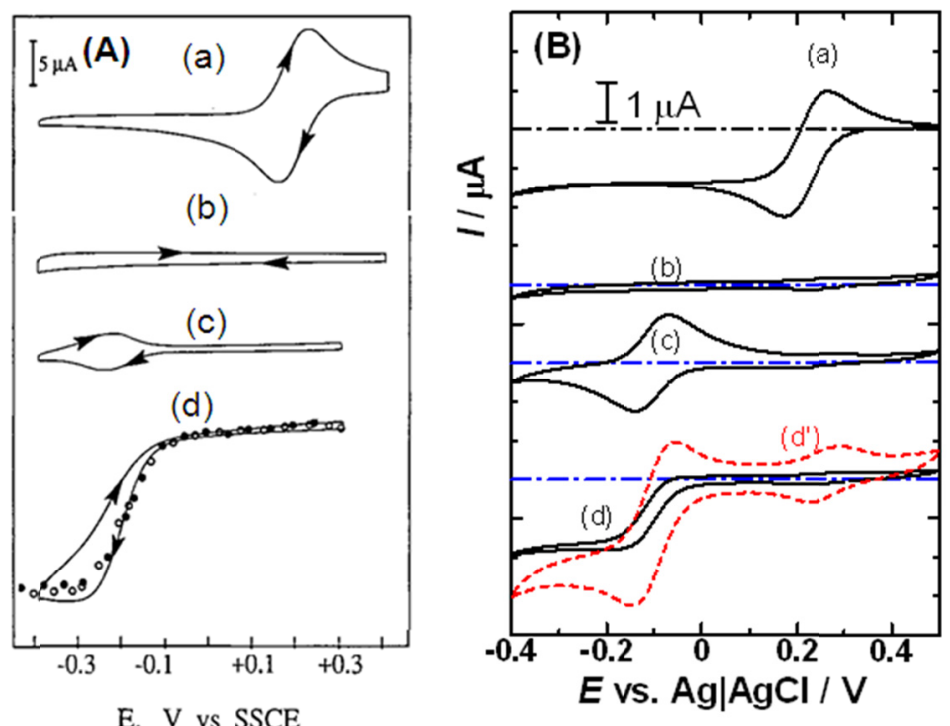

Figure 3. Voltammograms at the PGE by (A) Anson et al. (Shi \& Anson, 1998b) and (B) the present authors at $v$ $=5 \mathrm{mV} \mathrm{s}^{-1}$ under conditions of (a)-(d) in Figure 2. Wave (d') was obtained at $v=30 \mathrm{mV} \mathrm{s}^{-1}$. The NB film was 30 $\mu \mathrm{m}$. Voltammograms in (A) were re-plotted from Figure (2) of reference (Shi \& Anson, 1998b) so that the potential axis was common to that of (B)

Figure 4 shows voltammograms at various scan rates under condition (b) of Figure 2. The voltammetric run was started immediately after the $\{\mathrm{O}\}$-coated electrode was immersed into $\{\mathrm{W}\}$. Peaks were observed at the potentials ranging from 0.22 to $0.28 \mathrm{~V}$, which were close to the redox peak potentials of $\mathrm{Fe}(\mathrm{CN})_{6}^{3-4-}$ (in Figure $3(B)(a))$. No peak appeared in $\{\mathrm{W}\}$ without ferricyanide, implying that ferricyanide could penetrate into the oil 
phase to reach the electrode.

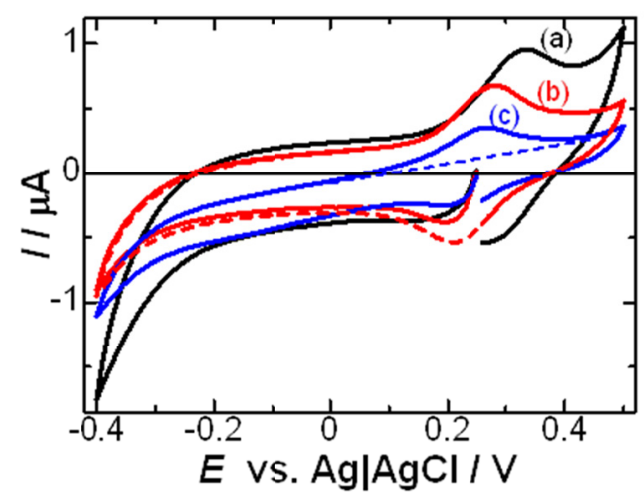

Figure 4. Voltammograms under condition (b) of Figure 2 at the $\{\mathrm{O}\}$-coated PGE in $4 \mathrm{mM} \mathrm{Fe}(\mathrm{CN})_{6}{ }^{3-}$ of $\{\mathrm{W}\}$ for $v=30$, (b) 20 and (c) $10 \mathrm{mV} \mathrm{s}^{-1}$, where the NB film was $15 \mu \mathrm{m}$ thick. The dashed line is the background current for evaluating the charge in curve (c)

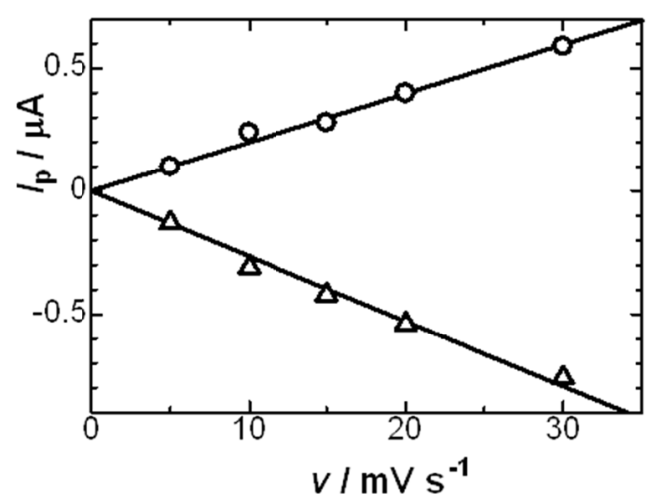

Figure 5. Variations of the cathodic and the anodic peak currents with the potential scan rate in Figure 4

Figure 5 shows the plot of the peak currents in Figure 4 against the scan rates, $v$, showing the proportionality. Therefore the peak currents should be controlled by the surface process, probably of adsorption of $\mathrm{Fe}(\mathrm{CN})_{6}{ }^{3 / 4-}$. It is the surface process that has made the peak clear at high scan rates. The surface process can be inferred from the potential difference between the anodic peak and the cathodic one $(30-40 \mathrm{mV})$ less than the diffusion-controlled potential difference $(60 \mathrm{mV})$. The area of the background-corrected peak current (the dashed line in Figure 4(c) for the background) may represent the redox charge in the film. We evaluated the anodic and the cathodic charges at the slowest scan rates to obtain $2 \times 10^{-10} \mathrm{~mol} \mathrm{~cm}^{-2}$ for the one-electron transfer reaction. This value corresponds to the area of $(1 \mathrm{~nm})^{2}$ per adsorbed molecule.

\subsection{Self-Emulsification}

The dry NB solution into which $\mathrm{K}_{3} \mathrm{Fe}(\mathrm{CN})_{6}$ was dispersed by ultrasonication did not show any voltammetric current. Therefore the peak current in Figure 4 should require a contact with aqueous phase. In order to find a visual evidence of whether water can transfer through the NB film, a NB drop which came in contact with water was mounted on a lithium plate. We found formation of bubbles on the lithium metal soon, as shown in photographs by the optical microscope in Figure 6. In contrast, a dry NB drop did not generate bubbles on the lithium plate. The bubbles should be hydrogen gas. The chemical reactivity suggests simple mixing of water with NB, as is similar to detection of acid in NB (Chung \& Anson, 2001). The other demonstration is detection of droplets by dynamic light scattering (DLS). After the NB phase came in contact with the aqueous phase for 50 min, a sampled NB phase showed DLS signal at diameters ranging from 1.6 to $3.0 \mu \mathrm{m}$. Therefore water droplets are confirmed to be generated. 


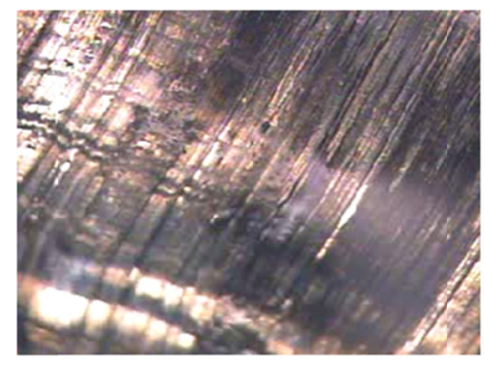

(A)

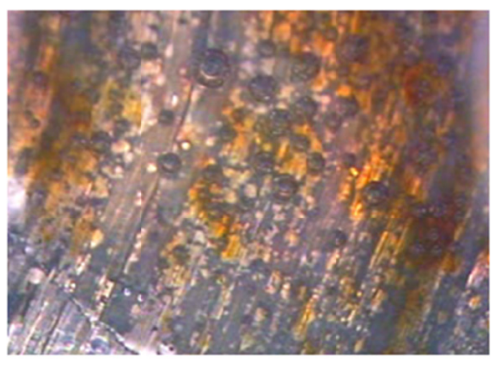

(B)

Figure 6. Photographs of the lithium metal surface $\left(4 \times 3 \mathrm{~mm}^{2}\right)$ coated into (A) the dry NB film and (B) the NB film with which water came in contact

It is interesting to know the concentration of penetrating water in NB. We used thermogravimetric analysis (TGA). An aliquot sampled from $\{\mathrm{O}\}$ in 30 min's contact with $\{\mathrm{W}\}$ was mounted on the TGA instrument. The variation of the weight and the heat flow with temperature are shown in Figure 7. The heat flow showed a minimum at $117{ }^{\circ} \mathrm{C}$ although the weight looked to decrease monotonically with the temperature. The enhancement of the evaporation temperature from $100{ }^{\circ} \mathrm{C}$ is ascribed to inclusion of the salts. The evaporation indicates that the water included NB should be in the state of thermally separable state. The weight loss before $117^{\circ} \mathrm{C}$ should be a sum of evaporated water and NB. We obtained the weight loss of NB by subtraction of the weight of the dried $\{\mathrm{O}\}$ (dashed curve in Figure 7). The net loss of water was $1.2 \mathrm{mg}$, of which concentration is $2 \mathrm{mM}$. This is the quantitative demonstration of the self-penetration of water. This technique has been used for detecting water droplets dispersed spontaneously into mercury under quiescent conditions (Aoki et al., 2012).

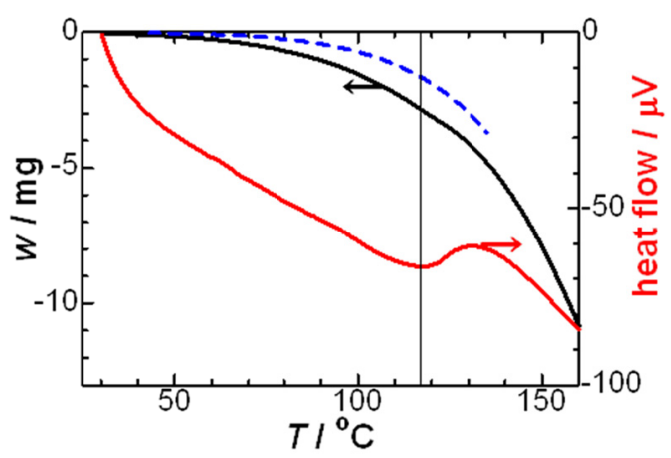

Figure 7. Temperature-dependence of weight and heat flow of $\{\mathrm{O}\}$ after contacting with $\{\mathrm{W}\}$ film for $30 \mathrm{~min}$. The dashed curve is for dry $\{\mathrm{O}\}$

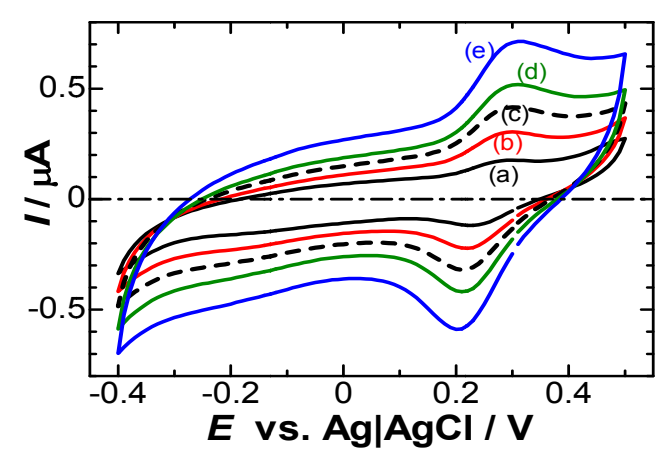

Figure 8. Voltammograms in the emulsion with the volume ratio of $20 / 1$ for $\{\mathrm{O}\} /\{\mathrm{W}\}$ for $v=$ (a) 5 , (b) 10 , (c) 15 , (d) 20 and (e) $30 \mathrm{mV} \mathrm{s}^{-1}$, where the $\{\mathrm{W}\}$ contained $4 \mathrm{mM} \mathrm{K}_{3} \mathrm{Fe}(\mathrm{CN})_{6}$ 
If water droplets participate in the adsorption of $\mathrm{Fe}(\mathrm{CN})_{6}^{3-4-}$ as shown in Figures 4-5, an artificially prepared emulsions including $\mathrm{K}_{3} \mathrm{Fe}(\mathrm{CN})_{6}$ should exhibit similar behavior. Emulsions with the volume ratio 20/1 of $\mathrm{NB} /$ water were prepared by mixing $\{\mathrm{O}\}$ with $4 \mathrm{mM} \mathrm{K}_{3} \mathrm{Fe}(\mathrm{CN})_{6}$-included $\{\mathrm{W}\}$ by means of ultrasonication for $10 \mathrm{~min}$. The suspensions were white turbid. The voltammograms are shown in Figure 8, being similar to those in Figure 4. The peak currents were proportional to $v$, being also similar to those in Figure 5. Therefore the behavior of the self-penetrated $\mathrm{K}_{3} \mathrm{Fe}(\mathrm{CN})_{6}$ is the same as that of the emulsions. However, redox waves of the emulsions sometimes appeared and sometimes disappeared, probably because of the formation of matrioshka-type droplets such as oil-in-water-in-oil droplets (Fukushima et al., 2009).

\subsection{Transport of Ferricyanide in Oil}

In order to estimate the transport rate of $\mathrm{Fe}(\mathrm{CN})_{6}{ }^{3-}$ from the oil|water interface to the electrode, we measured a period for $\mathrm{Fe}(\mathrm{CN})_{6}{ }^{3-}$ reaching the electrode from the interface. We started to make voltammetry in the potential domain of Figure 4 after the $\{\mathrm{O}\}$-coated electrode was immersed into $\mathrm{Fe}(\mathrm{CN})_{6}{ }^{3-}$-included $\{\mathrm{W}\}$. There was no redox peak immediately after the immersion. The redox peaks at ca. $0.25 \mathrm{~V}$ began to appear after several voltammetric scans. The time of the appearance of the peak can be regarded as the period for $\mathrm{Fe}(\mathrm{CN})_{6}{ }_{6}^{3-}$ to reach the electrode surface through the $\{\mathrm{O}\}$ film. We obtained the periods for several values of the thickness of the $\{\mathrm{O}\}$ films, $\delta$. Very thick films were required for determination of the period. The thickness determined with the microscope was plotted against the square-roots of the period, $t$, in Figure 9, exhibiting a proportional relation. Therefore, $\mathrm{Fe}(\mathrm{CN})_{6}{ }^{3-}$ should transport in the film by diffusion, obeyed by $\delta=(D t)^{1 / 2}$, where $D$ is a diffusion coefficient. The value of $D$ was $4 \times 10^{-5} \mathrm{~cm}^{2} \mathrm{~s}^{-1}$. If a $\mathrm{Fe}(\mathrm{CN})_{6}{ }^{3-}$ molecule in $\{\mathrm{O}\}$ has the same diameter as in $\{\mathrm{W}\}$, the diffusion coefficient in $\{\mathrm{O}\}$ is predicted to be $0.37 \times 10^{-5} \mathrm{~cm}^{2} \mathrm{~s}^{-1}$ from the Stokes-Einstein equation. The large value by the one order magnitude can be explained in terms of the enhancement of diffusion coefficients of sparingly soluble species, as being observed in ferrocene in water (Ouyang et al., 2013). The supersaturated species, of which free energy is higher than that of low concentrated species, diffuses to a low concentration domain rapidly in order to dissipate the excess energy of the supersaturation.

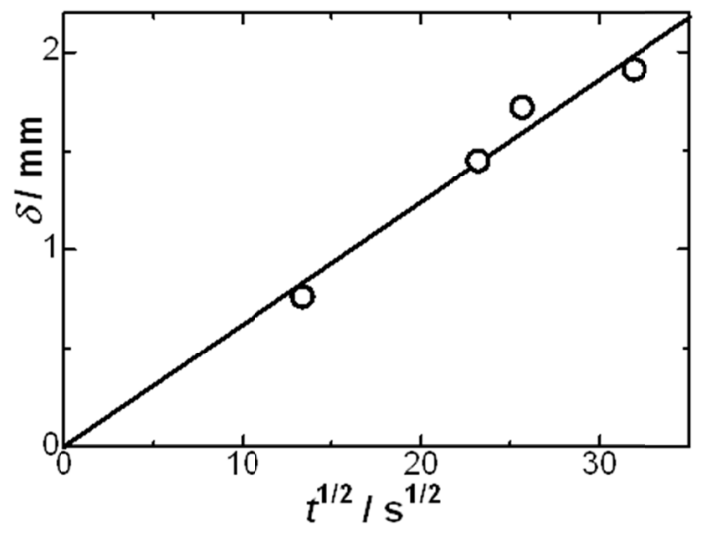

Figure 9. Variation of the thickness of $\{\mathrm{O}\}$ film on the PGE with the square-root of the period after which the redox wave at $0.25 \mathrm{~V}$ appeared from the beginning of immersion of the electrode in $\{\mathrm{W}\}$

We attempted to estimate an amount of penetrating $\mathrm{Fe}(\mathrm{CN})_{6}{ }^{3-}$ relevant to the catalytic reaction with $\mathrm{DMFc}$. The $\{\mathrm{O}\}$ phase including DMFc was in contact with the $\{\mathrm{W}\}$ phase including $\mathrm{Fe}(\mathrm{CN})_{6}{ }^{3-}$ for $1 \mathrm{~h}$. This $\{\mathrm{O}\}$ was dispersed on the electrode. As soon as the coated electrode was immersed into $\{\mathrm{W}\}$ without $\mathrm{Fe}(\mathrm{CN})_{6}{ }_{6}^{3-}$, a voltammetric run started. Since $\mathrm{Fe}(\mathrm{CN})_{6}{ }^{3-}$ was absent in $\{\mathrm{W}\}$ during voltammetry, Anson's model predicts no catalytic current, the value of which should be the same as in Figure 3(B)(c). Nevertheless, the observed voltammograms exhibited the cathodic peak at $-0.17 \mathrm{~V}$ by three times larger than the simple reduction wave of $\mathrm{DMFc}^{+}$at the first scan, as shown in Figure 10. The large current should be the catalytic reaction occurring only in the NB phase. It should be caused by penetrated $\mathrm{Fe}(\mathrm{CN})_{6}^{3-}$. The three times larger current corresponds to the sum of the twice catalytic current and the current by loaded DMFc $(0.5 \mathrm{mM})$. Therefore, rate constants of the electron exchange reaction determined by the surface catalytic reaction include volume reaction rates as Osakai suggested (Hotta et al., 2003; Osakai et al., 2004). 


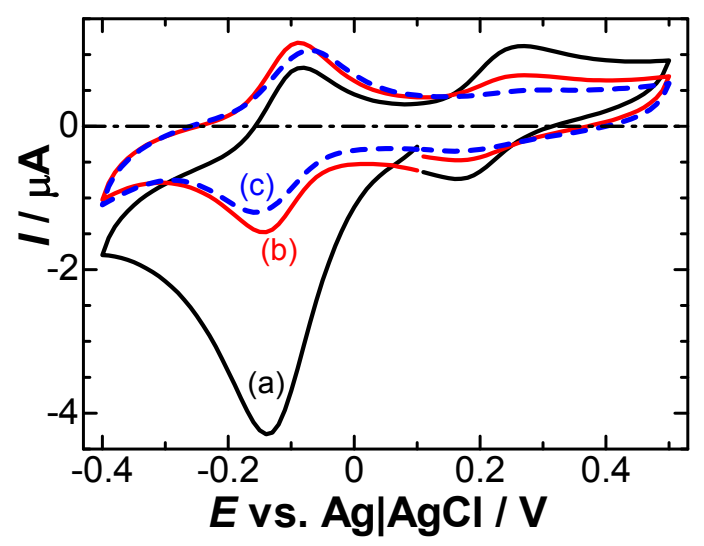

Figure 10. Voltammograms at $v=30 \mathrm{mV} \mathrm{s}^{-1}$ immediately after the transfer of the electrode to $\{\mathrm{W}\}$ without $\mathrm{Fe}(\mathrm{CN})_{6}{ }^{3-}$ at (a) the first, (b) the second and (c) tenth scan

\section{Conclusions}

The electrocatalysis by thin-oil films works efficiently at slow scan rates, as Anson et al did. Voltammograms at high scan rates, however, make the influence of self-emulsification remarkable. When a NB-coated electrode without any redox species is immersed in the aqueous solution including hydrophilic redox species and supporting electrolyte, the electrode reaction occurs by penetration of the hydrophilic species into the NB phase. The penetration is caused by diffusion, of which value is much larger than the conventional value. Consequently, the electron exchange reaction at the $\mathrm{NB}$ /water interface is not necessarily a rate-determining step but the reaction within the NB film is responsible for the current. The reaction at the interface is noticeable as the catalytic process at very slow scan rates, whereas the reaction within the NB film is remarkable at fast scan rates. The latter case may be used for be one of mechanisms of voltammetry at carbon paste electrodes.

\section{Acknowledgements}

This work was financially supported by Grants-in-Aid for Scientific Research (Grants 25420920) from the Ministry of Education in Japan.

\section{References}

Adams, R. N. (1958). Carbon Paste Electrodes. Anal. Chem., 30, 1576-1576. http://dx.doi.org/10.1021/ac60141a600

Aoki, K. (2011). Size-distribution of droplets in emulsions by statistical mechanics calculation. J. Colloid Interface Sci., 360, 256-261. http://dx.doi.org/10.1016/j.jcis.2011.04.054

Aoki, K., Li, C., Nishiumi, T., \& Chen, J. (2012). Self-dispersion of mercury metal into aqueous solutions. $J$. Electroanal. Chem., 682, 66-71. http://dx.doi.org/10.1016/j.jelechem.2012.07.003

Aoki, K., Li, M., Chen, J., \& Nishiumi, T. (2009). Spontaneous emulsification at oil-water interface by tetraalkylammonium chloride. Electrochem. Commun., 11, 239-241. http://dx.doi.org/10.1016/j.elecom.2008.11.012

Chung, T. D., \& Anson, F. C. (2001). Electrochemical Monitoring of Proton Transfer across Liquid/Liquid Interfaces on the Surface of Graphite Electrodes. Anal. Chem., 73, 337-342. http://dx.doi.org/10.1021/ac0009447

Ding, Z., Fermin, D. J., Brevet, P. -F., \& Girault, H. H. (1998). Spec-troelectrochemical Approaches to Heterogeneous Elec-tron Transfer Reactions at the Polarized Water/1,2-. Dichloroethane Interfaces. $J$. Electroanal. Chem., 458, 139-148. http://dx.doi.org/10.1016/S0022-0728\%2898\%2900341-6

Freire, M. G., Carvalho, P. J., Gardas, R. L., Marrucho, I. M., Santos L. M. N. B. F., \& Coutinho, J. A. P. (2008). Mutual Solubilities of Water and the $\left[\mathrm{C}_{\mathrm{n}} \operatorname{mim}\right]\left[\mathrm{Tf}_{2} \mathrm{~N}\right]$ Hydrophobic Ionic Liquids. J. Phys. Chem. B, 112, 1604-1610. http://dx.doi.org/10.1021/jp7097203

Fukushima, J., Tatsuta, H., Ishii, N., Chen, J., Nishiumi, T., \& Aoki, K. (2009). Possibility of coalescence of water droplets in W/O emulsions by means of surface processes. Colloids Surf. A, 333, 53-58. 
http://dx.doi.org/10.1016/j.colsurfa.2008.09.023

Gonzalez-Ochoa, H., Ibarra-Bracamontes, L., \& Arauz-Lara, J. L. (2003). Two-Stage Coalescence in Double Emulsions. Langmuir., 19, 7837-7840. http://dx.doi.org/10.1021/la0349323

Hotta, H., Ichikawa, S., Sugihara, T., \& Osakai, T. (2003). Clarification of the Mechanism of Interfacial Electron-Transfer Reaction between Ferrocene and Hexacyanoferrate(III) by Digital Simulation of Cyclic Voltammograms. J. Phys. Chem. B, 107, 9717-9725. http://dx.doi.org/10.1021/jp035058p

Kakiuchi, T., Tsujioka, N., Kurita, S., \& Iwami, Y. (2003). Phase-boundary potential across the nonpolarized interface between the room-temperature molten salt and water. Electrochem. Commun., 5, 159-164. http://dx.doi.org/10.1016/S1388-2481(03)00013-4

Kalcher, K. (1990). Chemically modified carbon paste electrode in voltammetric analysis. Electroanalysis., 2 , 419-433. http://dx.doi.org/10.1002/elan.1140020603

Kalcher, K., Kauffmann, J. -M., Wang, J., Švancara, I., Vytřas, K., Neuhold, C., \& Yang, Z. P. (1995). Sensors based on carbon paste in electrochemical analysis: A review with particular emphasis on the period 1990-1993. Electroanalysis, 7, 5-22. http://dx.doi.org/10.1002/elan.1140070103

Kuwana, T., \& French, W. G. (1964). Electrooxidation or Reduction of Organic Compounds into Aqueous Solutions Using Carbon Paste Electrode. Anal. Chem., 36, 241-242. http://dx.doi.org/10.1021/ac60207a006

Li, M., Aoki, K., Chen, J., \& Nishiumi, T. (2011). Voltammetric determination of concentrations of ferrocene-included nitrobenzene droplets in water. $J$. Electroanal. Chem., 655, 159-163. http://dx.doi.org/10.1016/j.jelechem.2011.02.015

Li, Y. Ch., Tsang, E. W., Chan, A. C., \& Yu, H. Zh. (2006). Thin-layer electrochemistry of 1,3,5-triferrocenylbenzene: A unique two-step, three-electron redox process. Electrochem. Commun., 8, 951-955. http://dx.doi.org/10.1016/j.elecom.2006.04.001

Liu, X. H., Hu, L. N., Zhang, L. M., Liu, H. D., \& Lu X. Q. (2005). Electron transfer between reactants ferric ion and decamethyferrocene located on $\mathrm{NB} / \mathrm{H}_{2} \mathrm{O}$ interfaces by thin layer method. Electrochim. Acta. 51, 467-473. http://dx.doi.org/10.1016/j.electacta.2005.05.006

Lu, X. Q., Zhang, L., Sun, P., \& Yao, D. (2011). Thin-layer cyclic voltammetric studies electron transfer across liquid/liquid interface. Eur. J. Chem., 2, 120-124. http://dx.doi.org/10.5155/eurjchem.2.1.120-124.273

Michael, C. P., Li, Y. Ch., Merbouh, N., \& Yu, H. Zh. (2008). Thin-layer electrochemistry of ferrocenylbenzene derivatives: Intramolecular electronic communication. Electrochim. Acta., 53, 7720-7725. http://dx.doi.org/10.1016/j.electacta.2008.05.043

Mirceski, V., Quentel, F., Lher, M., Spasovski, F., \& Gacina, M. (2007). Electrochemical study of hydrophilic ion transfers across cholesterol modified water-nitrobenzene interface by means of thin film electrodes. Electrochem. Commun., 9, 2489-2495. http://dx.doi.org/10.1016/j.elecom.2007.07.021

Osakai, T., Hotta, H., Sugihara, T., \& Nakatani, K. (2004). Diffusion-controlled rate constant of electron transfer at the oil/water interface. J. Electroanal. Chem., 571, 201-206. http://dx.doi.org/10.1016/j.jelechem.2004.05.010

Ouyang, C., Aoki, K. J., Chen, J., Nishiumi T., \& Wang, B. (2013). Determination of concentration of saturated ferrocene in aqueous solution. Reporst in Electrochem, 3, 17-23. http://dx.doi.org/10.2147/RIE.S48040

Pautot, S., Frisken, B. J., Cheng, J. -X., Xie, X. S., \& Weitz, D. A. (2003). Spontaneous Formation of Lipid Structures at Oil/Water/Lipid Interfaces. Langmuir, 19, 10281-10287. http://dx.doi.org/10.1021/la034532f

Ravichandran, K., \& Baldwin, R. P. (1981). Chemically modified carbon paste electrodes. J. Electroanal. Chem., 126, 293-300. http://dx.doi.org/10.1002/elan.1140020603

Sacanna, S., Kegel, W. K., \& Philipse A. P. (2007). Spontaneous Oil-in-Water Emulsification Induced by Charge-Stabilized Dispersions of Various Inorganic Colloids. Langmuir, 23, 10486-10492. http://dx.doi.org/10.1021/la701311b

Samec, Z., Kakiuchi, T. (1990). Advances in Electrochemical Science and Engineering. In H. Gerischer \& C.W. Tobias (Eds.), (Vol. 4, pp. 297). VCH, Weinheim.

Shchipunov, Y. A., \& Schmiedel, O. (1996). Phase Behavior of Lecithin at the Oil/Water Interface. Langmuir., 12, 6443-6445. http://dx.doi.org/10.1021/la960082y

Shi, C. N., \& Anson, F. C. (1998a). A Simple Method for Examining the Electrochemistry of Metalloporphyrins 
and Other Hydrophobic Reactants in Thin Layers of Organic Solvents Interposed between Graphite Electrodes and Aqueous Solutions. Anal. Chem., 70, 3114-3118. http://dx.doi.org/10.1021/ac980426k

Shi, C. N., \& Anson, F. C. (1998b). Simple Electrochemical Procedure for Measuring the Rates of Electron Transfer across Liquid/Liquid Interfaces Formed by Coating Graphite Electrodes with Thin Layers of Nitrobenzene. J. Phys. Chem. B, 102, 9850-9854. http://dx.doi.org/10.1021/jp982605b

Shi, C. N., \& Anson, F. C. (1999). Electron-Transfer Between Reactants Located on Opposite Sides of Liquid/Liquid Interfaces. J. Phys. Chem. B, 103, 6283-6289. http://dx.doi.org/10.1021/jp9911321

Solomont, T., \& Bard, A. J. (1995). Scanning Electrochemical Microscopy. 30. Application of Glass Micropipet Tips and Electron Transfer at the Interface between Two Immiscible Electrolyte Solutions for SECM Imaging. Anal. Chem., 67, 2787-2790. http://dx.doi.org/10.1021/ac00113a011

Sun, P., Li, F., Chen, Y., Zhang, M., Zhang, Z., Gao, Z., \& Shao, Y. (2003). Observation of the Marcus Inverted Region of Electron Transfer Reactions at a Liquid/Liquid Interface. J. Am. Chem. Soc., 125, 9600-9601. http://dx.doi.org/10.1021/ja0362297

Švancara, I., Vytřas, K., Kalcher, K., Walcarius, A., \& Wang, J. (2009). Carbon Paste Electrodes in Facts, Numbers, and Notes: A Review on the Occasion of the 50-Years Jubilee of Carbon Paste in Electrochemistry and Electroanalysis. Electroanalysis., 21, 7-28. http://dx.doi.org/10.1002/elan.200804340

Tsionsky, M., Bard, A. J., \& Mirkin, M. V. (1996). Scanning electrochemical microscopy. 34. Potential dependence of the electron-transfer rate and film formation at the liquid/liquid interface. J. Phys. Chem., 100, 17881-17888. http://dx.doi.org/10.1021/jp9612700

Tsionsky, M., Bard, A. J., \& Mirkin, M. V. (1997). Long-range electron transfer through a lipid monolayer at the liquid/liquid interface. J. Am. Chem. Soc., 119, 10785-10792. http://dx.doi.org/10.1021/ja972134r

Wang, R., Okajima, T., Kitamura, F., Matsumoto, N., Thiemann, T., Mataka, S., \& Ohsaka, T. (2003). Cyclic and Normal Pulse Voltammetric Studies of 2,3,6,7,10,11-Hexaphenylhexazatriphenylene Using a Benzonitrile Thin Layer-Coated Glassy Carbon Electrode. J. Phys. Chem. B, 10, 9452-9458. http://dx.doi.org/10.1021/jp0305281

Wei, C., Bard, A. J., \& Mirkin, M. V. (1995). Scanning electrochemical microscopy. 31. Application of secm to the study of charge-transfer processes at the liquid-liquid interface. J. Phys. Chem., 99, 16033-16042. http://dx.doi.org/10.1021/j100043a050

Xu, J., Frcic, A., Clybume, J. C., Gossage, R. A., \& Yu, H. Z. (2004). Thin-Layer Electrochemistry of 1,3-Diferrocenyl-2-buten-1-one: Direct Correlation between Driving Force and Liquid/Liquid Interfacial Electron Transfer Rates. J. Phys. Chem. B, 108, 5742-5746. http://dx.doi.org/10.1021/jp049104c

Yao, T., \& Musha, S. (1979). Electrochemical enzymatic determinations of ethanol and l-lactic acid with a carbon paste electrode modified chemically with nicotinamide adenine dinucleotide. Anal. Chim. Acta., 110, 203-209. http://dx.doi.org/10.1016/S0003-2670(01)93110-1

Zhang, J., Barker, A. L., \& Unwin, P. R. (2000). Microelectrochemical studies of charge transfer at the interface between two immiscible electrolyte solutions: electron transfer from decamethyl ferrocene to aqueous oxidants. J. Electroanal. Chem., 483, 95-107. http://dx.doi.org/10.1016/S0022-0728\%2899\%2900498-2

\section{Copyrights}

Copyright for this article is retained by the author(s), with first publication rights granted to the journal.

This is an open-access article distributed under the terms and conditions of the Creative Commons Attribution license (http://creativecommons.org/licenses/by/3.0/). 